\title{
Customers' Behavior towards Online Food Delivery Apps (FDAs) in Pune
}

\author{
${ }^{1}$ Dr. Varsha Bihade, ${ }^{2}$ Prof. Saylee Karande \\ ${ }^{1}$ Director and Professor, ${ }^{2}$ Asst. Professor, ${ }^{1,2}$ D.Y.Patil Institute of Management Ambi, Talegoan, \\ Pune India.
}

\begin{abstract}
A desire for an easy and comfortable lifestyle and busy schedules has boosted the demand for online food delivery applications. To spare the value time, avoid rush in restaurants and waiting time, many working consumers are now using the food delivery apps wherein they get ample of choices for food. And also they can compare the prices. The main focus of this research paper is to findout satisfaction level of customers using these applications with reference to pune and PCMC area. Most used popular apps such as ZOMATO, UBER Eats, Swiggy and Food Panda are taken into consideration during survey. The survey, based on the non-probability convenience sampling method was conducted by using the structured questionnaire. The study reveals that customers are satisfied with few factors and not with many and want to use this application because of ease in ordering the preferred food from favorite restaurants with reasonable perfections.
\end{abstract}

Key words:-customers, online food delivery, satisfaction, mobile, internet

\section{INTRODUCTION}

Technology in The Indian market is growing rapidly. One of the areas of technological growth is online food ordering apps. Things are becoming easier and faster because of technological advancements. The customers ordering food Online have been increasing rapidly in metro cities. In order to match-up with customer needs, keeping in view the busy schedule of customers; online delivery apps are providing better facilities for the convenience of the customers. Online food ordering is a process of delivering food from local restaurants with the help of mobile and internet applications.

Food delivery applications like Swiggy, Uber Eats, Zomato, and Food Panda provides innumerable varieties in different cuisines from different nearby restaurants. The payment for the food ordered and service provided either by credit card or cash, the restaurant returns a percentage of payment to the online food company/firm

Upon ordering food Online/through a mobile application, it provides a tracking system, wherein customers can track their food deliveries at each step. These applications are user-friendly, convenient and trusted.

Sources reveal that there has been a significant increase in restaurants and food businesses since users opt more for take-away and home delivery. Most users favor online apps as the food-on- click feature makes it possible to get food delivered right at their door instantly. This, in a way, has boosted the restaurant business widely.

\section{REVIEW OF LITERATURE}

1..Nick Johns (2002), the study examined the foodservice, an under-represented area in terms of four section, discussing survey work, experimental studies, and investigations of consumer behavior in the foodservice industry

2..Priyadharshini (2017) states that India has more individuals between the ages of 10 and 24, making it the world's biggest youth populace. With increasing youngsters entering the workforce every day, development in the economy, a rising female work power, and expanded portability among shoppers, the customarily troublesome Indian market has changed and is needing for a progressively assorted menu

3..H.S. Sethu\& bhavya saini "Customer Perception and Satisfaction on Ordering Food". (2016): The study revealed that the online food ordering services were used by 100 percent of the respondents, and the buying decisions were largely influenced by the opinions of a friend's family and discussions on online forums. The study reveals that good word of mouth and experiences by existing customers and online forums decide the success of web based food shopping

4..According to Deepinder Goyal, Zomato CEO and cofounder told TechCrunch that he expects to reach 10,000 restaurants in India in a few months. "We have a sales team of around 300 in India and 5,000-odd advertisers... these partners know the volume we bring to them so it is quite easy for us to launch this new service." 
5..J. Das(2018) has studied, analyzed and compared the top 4 food delivery apps namely, Zomato, Swiggy, Foodpanda and Ubereats. Providing better discounts" and "better choices of restaurants", Zomato is positioned at the top by the customers. Zomato is also positioned at the top by the customers while considering delivery on time and good customer service. In both situations, customers ranked Ubereats at the last position

6..According to a January 28 report in The Times of India, Rocket Internet-backed Foodpanda has not found a buyer even with a rock bottom price tag of \$10-15 million. The company laid off 300 people in December 2015, about $15 \%$ of its workforce. In September 2015, TinyOwl had fired 100 employees in its Mumbai and Pune offices. And in October, Zomato sacked 300 workers

The UK based Just Eat entered and exited the market faster than you would order and receive pizza.

7..Pathan et al. (2017) state that with the online food ordering system, a restaurant and mess menu online can be set up and the customers can easily place an order. Also with a food menu online, orders can be easily tracked, it uphold customers' database and develop the food delivery service. The restaurants and mess can even modify the online restaurant menu and upload images easily. Having a restaurant menu on the internet, potential customers can easily access it and place an order at their convenience. Thus, an automated food ordering system is presented with features of feedback and wireless communication.

8. Sainath Reddy K, Chaitanya KGK, Abhinav $M$ and Feiroz Khan $\mathrm{TH}(2016)$, the authors observed that the system was successful in overcoming the problems by cost effective development in the field of on-line food service.

9. Anh Kim Dang (2018), the study suggested the consumers whenever purchasing the desire food products on the Internet, to online food retailer to implement appropriate legislation regarding trading through legalized way

10.According to Hong Lan, et al, (2016), online food delivery market is immature yet; there are some obvious problems that can be seen from consumers ${ }^{e e}$ negative comments. In order to solve these problems, we can neither rely merely on the self-discipline of online food delivery restaurants nor the supervision and management of online food delivery platforms. Only by taking laws as the criterion, with the joined efforts of the online food delivery platforms and restaurants, the government departments concerned, consumers and all parties in the society, can these problems be solved and a good online take away environment can be created.

\section{Objectives}

1. To study the significant behavioral fats of online buyers using FDAs

\section{RESEARCH DESIGN}

The data has been collected from primary and secondary sources.

Primary data consists of information collected through a structured questionnaire based on the satisfaction of customers using food delivery apps in Pune and PCMC.

Secondary data consists of collecting information about various apps, the industry position, portals from the internet, journals, magazines etc.

The survey was conducted in different areas of Pune and PCMC, and around 89 responses were d.. For all variables used in the study, multi-item scales (5-point, Likerttype) ranging from strongly agree (5) to strongly disagree (1) are used.

The population consist of the students, self-employed, homemaker, private company employee and business owners of different areas in Pune

The list (sampling frame) of on line buyers (> 3000 in numbers) buying food items through FDAs in the Month of November 2019 was prepared by contacting FDAs offices in Pune.Out of these 3000 respondents, 89 respondents were interviewed under the experience survey by using convenience sampling technique. After interviewing 89 respondents, it is realized that further interviews i.e. $>89$ would be voicing of similar replies and hence it is costlier and time-consuming (and also wasteful too!) to examine an additional number of respondents. As a result the sample size is happened to be 89 respondents who are users of FDAs

For all variables used in the study, multi-item scales (5point, Likerttype) ranging from strongly agree (5) to strongly disagree (1) are used.

The sampling method is non-Probability convenience sampling, the Research design is a mix of exploratory and Descriptive types.

\section{DATa ANAlysis}

Family size Table No:-1 Family size of sample customers (n-89) using FDAs

\begin{tabular}{|l|l|c|}
\hline Sr.No. & Family Size & $\mathrm{N}=89$ \\
\hline 1 & Up to 3 & 34 \\
\hline 2 & $3-5$ & 43 \\
\hline 3 & 5 and above & 23 \\
\hline & Total & 100 \\
\hline
\end{tabular}

\section{Source: Field Survey}

As pertains to the family size of the customers availing the services of different FDA types, it is seen that the maximum $43 \%$ of sample customers are from the family size 3-5 and 
$34 \%$ from family size 3-5 while a smaller percentage of $23 \%$ are from the family size 5 and above. Thus, the families having a large size are less inclined to in using FDAs as compared to other smaller size families

\section{Educational level}

Table No :-2 Educational Level of the sample customers (n-89) using FDAs

\begin{tabular}{|l|l|c|}
\hline Sr.No & Educational Level & $\mathrm{N}=89$ \\
\hline 1 & Below high school & $6 \%$ \\
\hline 2 & High School & $4 \%$ \\
\hline 3 & Graduation & $26 \%$ \\
\hline 5 & Post-Graduation & $34 \%$ \\
\hline 6 & Professional degree & $30 \%$ \\
\hline & Total & $100 \%$ \\
\hline
\end{tabular}

Source: Field Survey

It is seen from the above table and graph that the maximum number of customers using the FDAs are having graduations $(26 \%)$, Post-Graduation $(34 \%)$ or professional degrees $(30 \%)$; while customers percentages having high school $(4 \%)$ or below high school $(6 \%)$ education appear petite. It means that mostly FDAs Users are from the highly educated category.

\section{Occupation}

Table No:-3 Occupational Sectors of sample customers using FDAs

\begin{tabular}{|l|l|c|}
\hline $\begin{array}{l}\text { Sr. } \\
\text { No }\end{array}$ & $\begin{array}{l}\text { Working } \\
\text { Sectors }\end{array}$ & $\mathbf{n = 8 9}$ \\
\hline 1 & Govt. & $34 \%$ \\
\hline 2 & Private & $31 \%$ \\
\hline 3 & Service & $23 \%$ \\
\hline 5 & Farming & $12 \%$ \\
\hline & Total & $100 \%$ \\
\hline
\end{tabular}

Source: Field Survey

FDAs are used by the maximum number of customers (34\%) from the Govt. sector followed by Private (31\%), service $(23 \%)$ and Farming (12\%) sector.

\section{Financial position}

The financial position of a person plays a crucial role in promoting an individual to avail the services of different types of hotels. On the basis of their incomes, the sample Customers using FDAs are grouped into three categories as shown in the following table

Table No.:-4 Income Level of the sample customers $(n=$ 89 ) using FDAs for ordering

\begin{tabular}{|l|c|c|}
\hline $\begin{array}{l}\text { Sr. } \\
\text { No. }\end{array}$ & $\begin{array}{c}\text { Annual Income } \\
\text { Rs. in lakhs }\end{array}$ & $\mathbf{N = 8 9}$ \\
\hline 1 & Up to 3 & 12 \\
\hline 2 & $3-5$ & 22 \\
\hline
\end{tabular}

\begin{tabular}{|l|l|l|}
\hline 3 & $5-10$ & 24 \\
\hline 4 & 10 and above & 42 \\
\hline & Total & \multicolumn{1}{|c|}{$\mathbf{1 0 0}$} \\
\hline
\end{tabular}

Source: Field Survey

- Note:-Online users of FDA is assumed as any member in family buying the food by using the income of the family

It is seen from the above table that the larger Proportions of customers using FDAs are in the higher annual income group; thus $42 \%$ of sampled customers are from the annual income group of Rs. 10 lakhs+ followed by $24 \%$ from Rs. 5-10 , 22\% from Rs. Rs.3-5 and 12\% from annual income group of up to Rs. 3 lakhs

\section{Domicile of customers}

Table No.:-5 \% of sample customers from different domiciles using FDAs

\begin{tabular}{|l|l|c|}
\hline Sr.No & Domicile & $\mathbf{N = 8 0}$ \\
\hline 1 & Abroad & $02 \%$ \\
\hline 2 & Out of state & $44 \%$ \\
\hline 3 & within Maharashtra & $32 \%$ \\
\hline 4 & Pune it-self & $24 \%$ \\
\hline & Total & $\mathbf{1 0 0 \%}$ \\
\hline
\end{tabular}

Source: Field Survey

FDAs are used by the maximum number of customers (44\%) having domiciles out of the state followed by Domicile status as within Maharashtra (32\%), Pune itself (24\%) and $2 \%$ of customers at abroad (02\%).Thus Punait, as compared to respondents having domicile either outside Pune or Sate are less in proportion for making the use of FDAs while foreigners stand with negligible proportion

Customer Loyalty

Table No.:-6 APIs wise Distribution of customer's loyalties towards various FDAs

\begin{tabular}{|l|l|l|}
\hline Sr.No & FDAs & APIs in $\%(\mathbf{n = 8 9})$ \\
\hline 1 & Swiggy. & $56 \%$ \\
\hline 2 & Zomato Order. & $78 \%$ \\
\hline 3 & Uber Eats. & $67 \%$ \\
\hline 4 & Foodpanda. & $47 \%$ \\
\hline 5 & Domino's. & $37 \%$ \\
\hline 6 & Pizza Hut. & $36 \%$ \\
\hline 7 & Just Eat. & $67 \%$ \\
\hline 8 & Faaso's. & $47 \%$ \\
\hline
\end{tabular}

Source: Field Survey

Note:-each respondent is asked to quote an Average Perceive Intensity (API) of purchasing through given FDA where zero \% means "Nil" purchasing Loyalty and 100\% mean "full " Purchasing Loyalty and any \% in between these two extremes unveils the level of loyalty in the percentage towards given FDA .The ultimate Average 
Perceived intensities (APIs) for given FDA reveal an average value for the sample group $(n=89)$ ( This mapping logic is based on Likert extended 100 point scale )

It is seen from the above table customer loyalty APIs is the highest for Zomato Order(78\%) followed by Uber Eats (67\%),Just Eat

(67\%),Swiggy(56\%),Foodpanda(47\%),Faaso's

(47\%)Domino's,(37\%), and the last Pizza Hut (36\%).

\section{Reasons for using FDAs}

It is observed that, the customers using FDAs are coming with varied Reasons other than simply food consumption.

Table No.:-7 Distribution of sample FDAs' customers $(n=89)$ as per major Reasons

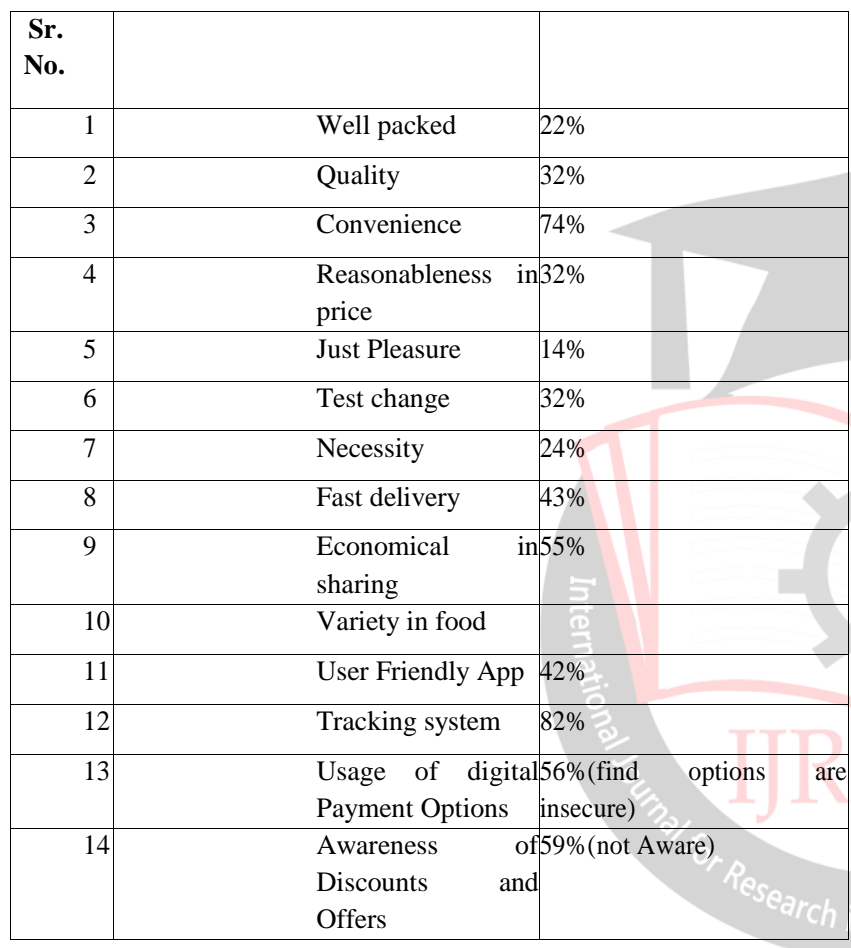

\section{Source: Field Survey}

There are a number of reasons endorsed by respondents for purchasing through FDAs ;Thus well gpacking (22\%), Quality(32\%), Convenience (74\%), Reasonableness in price (32\%),Just

Pleasure(14\%), Test change(32\%),Necessity(24\%),Fast delivery(43\%) and Economical in sharing economics is the dominant reason while buying through FDA

\section{Other equally important Derivations from the data}

Looking the need to keep limited length and breadth of the research papers in printable version, the researchers, unlike forgoing (Table No-1 to 7) has endeavored to condense the findings from the duly tabulated data in nutshell as ahead:-

89 sample Customers using FDAs are instrumental / informative to arrive at the following findings:-

1. $73 \%$ of the respondents are male.
2. $43 \%$ of respondents are above 25 years and $33 \%$ respondents are above 35 years.

3. $12 \%$ of students and $23 \%$ of service people use FDAs as a necessity

4. $42 \%$ of respondents find these FDAs excellently user-friendly, $43 \%$ consider food quality and hygienist as excellent, while $45 \%$ of respondents perceive time efficiency.

5. Normally and approximately, 5\% of respondents use FDAs for breakfast, $42 \%$ respondents for Lunch while $50 \%$ for dinner

6. Quality of food is considered to be very good by $78 \%$ of respondents

7. The tracking system is considered excellent by $82 \%$ respondents

8. Available Payment options are good according to $56 \%$ of respondents, still many use COD due to security reasons

9. $64 \%$ of respondents consider they may have more options for restaurants

10. $59 \%$ of respondents are not aware of offers/ discounts on FDAs

\section{CONCLUSION}

Online services are gaining fast platform in all the sectors, and, food delivery Apps is one among them. These Apps are mostly chosen by higher income group, mostly by youth. Swiggy and Uber Eats food delivery Apps have captured market to large extent in Pune and PCMC areas. Though popular still these Apps are not able to deliver food in estimated time,Moreover online payment modes are used very less by customers due to fear of insecurity towards online fraud. Food Delivery Apps give many offers/discounts in order to attract customers, but they are not known/ less awareness is among the customers

\section{SUGGESTIONS}

1. Though most of the respondents are satisfied with the services of Food delivery Apps, still the majority of them are not using Apps, Companies should promote, everyone to use the App

2. Apps are user-friendly, but, most of them using are youth. Even older age group people should be encouraged to use the apps

3. Respondents are not comfortable paying online, they should be educated on the security of digital payments

4. The focus should be more on the timely delivery and quality of food. 
5. Most of them are not aware of offers/discounts on applications, the focus should be more on promoting them to increase the usage.

\section{LIMITATIONS}

Research is limited to Pune only and covers a small number of respondents (>3000) who used FDAs in the Month of November 2019. However, the population of respondents is fairly homogeneous in conformity to objectives and hence the derivations/conclusions/suggestions are universal in any analogs environment.

\section{REFERENCES}

[1] Nick Johns(2002) - "Consumer Behavior in the Food Service Industry" - International Journal of Hospitality Management 21(2): 110 - 134 June 2002

[2] R., Priyadharshini. (2017). Consumer perception towards MNC fast food outlets in Coimbatore. International Journal of Applied Research,3(3). Retrieved from http://www.allresearchjournal.com/archives/2017/vol3i ssue3/PartD/3-3- 54-357.pd

[3] H.S. Sethu, Bhavya Saini,“Customer Perception and Satisfaction on Ordering Food via Internet, a Case on Foodzoned.Com, in Manipal", Published by, [Online] Available: http://www.globalbizresearch.org

[4] Das J., 2018, Consumer perception towards online food ordering and delivery services: an empirical study, Journal of Management, 5, Vol. 5, page no. 158-162

[5] R., A., Singh, A., Pathan, S., \& Kanade, V. (2017). Online Food Ordering System. International Journal of Computer Applications, 180(6), ? 22-24. doi:10.5120/ijca2017916046

[6] Sainath Reddy K, Chaitanya KGK, Abhinav M and Feiroz Khan TH(2016) "An Online Food Court Ordering System" - Open Access Journal

[7] Anh Kim Dang (2018) "Consumer Preference and Attitude Regarding Online Food Products in Hanoi, Vietnam" - International journal for Environment Research and Public Health May 2018 15(5)

[8] Hong Lan, Li Yaenan \& Wang Shuhua (2016), "Improvement of Online Food Delivery Service Based on Consumers" Negative Comments", Canadian Social Science, Vol. 12, No. 5, pp. 84-88 